BMJ Nutrition,

Prevention \& Health

\section{Nutrition and lifestyle intervention in type 2 diabetes: pilot study in the Netherlands showing improved glucose control and reduction in glucose lowering medication}

\begin{abstract}
- Additional material is published online only. To view please visit the journal online (http://dx.doi.org/10.1136/ bmjnph-2018-000012).

For numbered affiliations see end of article.
\end{abstract}

Correspondence to Dr Gerda K Pot, Louis Bolk Instituut, Bunnik 3981 AJ, The Netherlands; g.pot@louisbolk.nl

Received 24 October 2018 Revised 2 April 2019 Accepted 4 April 2019 Published Online First 14 May 2019
Check for updates

(C) Author(s) (or their employer(s)) 2019. Re-use permitted under CC BY-NC. No commercial re-use. See rights and permissions. Published by BMJ.

To cite: Pot GK, BattjesFries MCE, Patijn ON, et al. bmjnph 2019;2:43-50.

\section{ABSTRACT}

Introduction Prevalence of type 2 diabetes (T2D) is increasing rapidly and lifestyle interventions to reverse diabetes are seen as a possible solution to stop this trend. New practice-based evidence is needed to gain more insight in the actual, and above all scientific, basis for these claims.

Methods This observational study with a pretest posttest design aimed to pilot a 6-month multicomponent outpatient group-based nutrition and lifestyle intervention programme on glycaemic control and use of glucose lowering medication in motivated T2D patients with a body mass index $(\mathrm{BMl})>25 \mathrm{~kg} / \mathrm{m}^{2}$ in the Netherlands (February 2015-March 2016).

Results 74 T2D patients ( $56 \%$ female) aged $57.4 \pm 8.0$ years with mean BMl $31.2 \pm 4.2 \mathrm{~kg} / \mathrm{m}^{2}$ and mean waist circumference $105.4 \pm 10.2 \mathrm{~cm}$ were included in the study. Compared with baseline, mean $\mathrm{HbA1c}$ levels at 6 months were $5 \mathrm{mmol} / \mathrm{mol}$ lower $(\mathrm{SD}=10, \mathrm{p}<0.001)$ and the number of participants with $\mathrm{HbA} 1 \mathrm{c}$ levels $\leq 53 \mathrm{mmol} / \mathrm{mol}$ after intervention had increased (from $36 \%(n=26 / 72)$ to $60 \%$ $(n=43 / 72))$. At baseline, $90 \%$ of participants were taking at least one type of glucose lowering medication. At 6 months, $49 \%(n=35 / 72)$ of the participants had reduced their medication or eliminated it completely $(13 \%)$. Secondary outcomes were significantly lower fasting glucose levels $(-1.2 \pm 2.6 \mathrm{mmol} / \mathrm{L})$, body weight $(-4.9 \pm 5.1 \mathrm{~kg})$, BMI $\left(-1.70 \pm 1.69 \mathrm{~kg} / \mathrm{m}^{2}\right)$ and waist circumference $(-9.4 \pm 5.0 \mathrm{~cm})$. Plasma lipids remained unchanged except for a decrease in triglyceride levels. Furthermore, self-reported quality of life was significantly higher while experienced fatigue and sleep problems were significantly lower.

Conclusion This pilot study showed that a 6 -month multicomponent group-based program in a routine care setting could improve glycaemic control and reduce the use of glucose lowering medication in motivated T2D diabetics. A fully scaled study is needed to confirm these results.

\section{INTRODUCTION}

The prevalence of type 2 diabetes (T2D) has seen an exponential rise during the last

\section{What this paper adds}

- While lifestyle interventions are seen as possible solutions to stop the increasing trend in type 2 diabetes, studies backing this up are rare.

- This pilot study of a 6-month lifestyle programme $(n=74)$ showed that participants used less glucose-lowering medication and $\mathrm{Hb} 1 \mathrm{Ac}$ levels dropped significantly.

- 'Reverse Diabetes2' focusses on lifelong changes in nutrition (unprocessed food, no calorie counting), stress management and physical activity.

decades. ${ }^{1}$ It is probable that lifestyle-related factors are the dominant cause, together with the ageing of the population and a genetic predisposition. ${ }^{2}$ Among lifestyle factors, metabolically unhealthy eating habits play a key role in the aetiology and progression of T2D. ${ }^{34}$ Therefore, it would be logical to give nutrition and lifestyle a prominent place in T2D prevention and treatment. ${ }^{5} \mathrm{~T} 2 \mathrm{D}$ is potentially reversible, as reflected by normalised $\mathrm{Hb} 1 \mathrm{Ac}$ levels and a reduction and/or elimination of T2D medication. ${ }^{6}$ The latter could also be called drug-free remission of T2D. Sustained remission of T2D comes with improved physical health and well-being of the patient, fewer comorbidities and a considerable reduction in medical costs. Interventions to reverse T2D so far were based on (1) bariatric surgery, ${ }^{78}$ (2) very low-calorie diets ${ }^{9}{ }^{10}$ or (3) nutritional ketosis. ${ }^{11-14}$ A major limitation of the latter two options is that they are based on data from studies with a number of shortcomings, for example, being relatively short in duration, ${ }^{12} 15$ performed in relatively small populations, ${ }^{10-13}$ not leading to long-term changes or reversal of T2D, ${ }^{16-20}$ and/or that long term 
adherence to these strategies is relatively low. ${ }^{9} 18$ 21-23 Moreover, none of these studies assessed T2D medication use as a primary outcome. General lifestyle intervention studies, including nutrition, physical activity and stress reduction, in T2D are even rarer. The studies that have been performed showed long-term improvements. ${ }^{24-26}$

Common arguments against lifestyle management as part of standard clinical practice includes that a lack of patient motivation hampers the sustainability of any potential results, that it would be impractical, and that effectiveness in primary care is not supported by evidence. Indeed, studies in primary care settings that show the efficacy of lifestyle interventions are relatively scarce. ${ }^{27}$

The objective of this study was therefore to pilot a newly developed 6-month multicomponent programme providing intensive counselling on nutrition and lifestyle, a digital coaching and education platform, physician-guided medication management and cooking classes. This programme is called 'Reverse Diabetes2' (In Dutch 'Keer Diabetes2 $\mathrm{Om}^{\prime}$ ) and has been developed by the Foundation Nutrition Alive (In Dutch 'Voeding Leeft'). The novelty of this programme lies in its multicomponent character. This includes providing skills rather than just knowledge of nutrition and lifestyle, in its individual approach using biometric feedback, and its use of a group-based approach. In addition, the programme uses a dynamic 'proof of practice' approach ${ }^{28}$ and therefore is continuously updated as insights on T2D develop over time. ${ }^{29}$ The study hypothesis was that T2D patients would significantly reduce their Hb1Ac levels and use of glucose lowering medication in response to the 6-month multicomponent multidisciplinary programme.

\section{METHODS}

\section{Study population}

Patients who completed the 'Reverse Diabetes2' programme (see below) between February 2015 and March 2016 were enrolled in this observational study. Informed consent was provided by both the patient and their general practitioner (GP). Patients were included using a stepped-wedge design with approximately 20 patients per group starting each month per location (a so-called convenience sample). Inclusion criteria were diagnosis of T2D mellitus, age 18-75 years, body mass index (BMI) $25-41 \mathrm{~kg} / \mathrm{m}^{2}$, ability to speak Dutch fluently and motivation to take part in a lifestyle intervention programme. Exclusion criteria were a diagnosis of type 1 diabetes, use of an insulin pump, serious comorbidities, for example, a severe form of chronic obstructive pulmonary disease (COPD) (Gold III or IV), bariatric surgery, eating disorders, heart failure (class 2-4), or kidney failure (estimatedglomerular filtration rate (eGFR)/modification of diet in renal disease (MDRD), eGFR/MDRD $<45$ unit). The study was approved by the Institutional Review Board of Healthcare partners Friesland. Medication use of participants was always managed by a healthcare professional (GP) in accordance with standard medical practice. The investigators had no influence on possible changes in glucose lowering medication.

\section{Lifestyle intervention programme}

The programme 'Reverse Diabetes2' is a 6-month lifestyle intervention programme developed with the aim to help T2D patients regain control over their disease by improving lifestyle and nutrition. In this programme, people with T2D are supported and empowered by providing them with knowledge and skills to structurally adapt their dietary habits and general lifestyle. This intervention programme distinguishes itself from regular healthcare for T2D patients in the Netherlands by its group-based setup, intensity of knowledge transfer, structural focus on stress reduction, a cooking class and internet-based community building. Guidance is provided for a period of 6 months by a multidisciplinary support team, comprising a dietician, a personal coach and a nurse practitioner in collaboration with the patient's GP. Partners and family of the patients were also actively involved in the process as this has been shown to improve the effectiveness of lifestyle intervention programmes. ${ }^{30}$ The cause and underlying physiology of T2D was explained and specific attention was paid to aspects such as developing cooking skills, managing stress, mental obstacles and exercise routines. Above all, an important principle of the group programme was that participants as well as their partners were encouraged to support each other, and share their experiences, which has been shown to improve the effectiveness of lifestyle intervention programmes. ${ }^{30}$ To this end, social media like Facebook and WhatsApp were used to establish online communities. Participants also received instant biometric feedback, by routinely measuring their blood glucose levels after meals, via blood measurements performed by their own GP and by regularly measuring their waist circumference. ${ }^{31}$ The core of the programme is nutritional advice, which is based on the evidence-based dietary guidelines from the Dutch Diabetic Federation for T2D ${ }^{32}$ and includes an increased consumption of fresh, unprocessed foods with high nutritional value and healthy natural fats, while being low on high glycaemic (rapidly absorbable) carbohydrates. Instead, consumption of low glycaemic index carbohydrates was encouraged. It is important to note that the diet was neither a calorie-restricted nor a high-fat diet. Practical guidance was tailored to the individual's preference, that is, each person was encouraged to find his/her own preferred dietary choices. To enhance participants' compliance with the programme, they were asked for a financial contribution towards programme costs (€295 of which $€ 100$ was reimbursed when participants had completed all questionnaires and was waived if this contribution hindered highly motivated people with budgetary restraints from participating).

The programme started with a 2-day group training, always taking place in a quiet place in the country. After 1 month, 3 months and 6 months, respectively, groups were invited for day-long follow-up meeting. Group members 
were encouraged to keep in regular contact with each other and the support team using social media such as Facebook and WhatsApp. ${ }^{30}$

\section{Study design}

A pretest posttest design was used to pilot the pilot programme 'Reverse Diabetes2'. The analyses presented in this study included patients diagnosed with T2D, who completed the 6-month programme and completed both baseline and follow-up questionnaires on health, quality of life, T2D parameters (measured by a healthcare professional such as nurse practitioner or GP) and programme adherence. One week prior to the start of the programme and 1 week before the final meeting, participants received an email with an invitation and link to complete an online questionnaire. The primary outcome measures of the study were Hb1Ac levels and the use of glucose lowering medication; secondary outcomes included other T2D biomarkers including self-reported blood lipid profile (fasting glucose, cholesterol), height, weight, waist circumference, programme adherence and appreciation, subjective health parameters and physical activity levels.

A power calculation based on the primary outcome Hb1Ac values, with a mean difference of $5 \mathrm{mmol} / \mathrm{mol}$ (matched pairs) and a SD of $11 \mathrm{mmol} / \mathrm{mol}$ (based on unpublished but self-collected data, 2014) with alpha 0.05 and beta 0.95 (two-sided) showed that 46 participants were needed.

\section{Primary outcome measures: glucose regulation (HbA1c) and glucose lowering medication use}

HbA1c levels were measured by the participant's GP or nurse practioner, and glucose lowering medication was prescribed according to the Dutch GPs guideline standards (Nederlands Huisartsen Genootschap [NHG]). ${ }^{33}$ The participants reported this information to the investigators; there was no direct data-exchange between GPs and investigators. Medication use was assessed by asking the participants to report on the dose and frequency of their current glucose lowering medication. Glucose lowering medication use was classified as 0 (no medication), 1 (only Metformin), 2 (sulfonylureum [SU]-derivate and Metformin) and 3 (insulin and SU-derivate and Metformin). Both parameters were assessed at baseline and 6 months.

\section{Secondary outcome measures}

Secondary outcome measures included fasting blood glucose, cholesterol (high-densitylipoprotein [HDL], low-density lipoprotein [LDL], triglycerides), height, weight, waist circumference, programme adherence and appreciation, subjective health parameters and physical activity levels. Participants were asked to report the most recently measured values, by their GP or nurse practioner, according to the Dutch GPs guideline standards (NHG) ${ }^{33}$ Perceived health and quality of life were assessed with a 10-point Likert scale (eg, how do you rate your health/ quality over the past 14 days on a scale from 1 to 10 ?). The validated 'Checklist Individual Strength (CIS)' questionnaire $^{34}$ to assess experienced fatigue during the past 2 weeks on a 7-point scale (ranging from (not) to (very applicable)). Sleep problems and physical activity (moderate and intense, over the past 14 days) were assessed with a 5-point Likert scale (eg, have you experienced any sleep problems and/or have you performed moderate or intense physical activity?). Programme adherence and appreciation were assessed with a 5-point Likert scale per mealtime (breakfast, lunch, dinner, snacks and drinks) (ranging from (not) to (almost fully)). Programme appreciation was assessed with a 10-point Likert scale. Furthermore, information on date of birth, sex, education level (highest achieved level classified as low/middle or higher education level) and family structure (married/cohabiting or single with or without children living at home) was collected at baseline.

\section{Statistical analyses}

SPSS (V.23.0) was used for conducting the statistical analyses. First, descriptive analyses were performed to describe the sociodemographic characteristics of the participants. Data were described as mean $\pm \mathrm{SD}$, as they were normally distributed, or n (percentage). Next, paired sample t-tests were performed on change in each measured parameter (follow-up minus baseline). Furthermore, stratified analyses on HbA1c were performed on participants with HbAlc-values below ('low starters') or above $53 \mathrm{mmol} /$ mol at baseline ('high starters'), as this HbA1c-value is seen as a target value for T2D patients. ${ }^{6}$ Results were interpreted as statistically significant when $\mathrm{p}<0.05$ (two-sided). Missing data were treated according to the per-protocol approach.

\section{RESULTS \\ Subjects}

Four groups each consisting of $15-20$ patients $(n=74)$ started the programme. One participant dropped-out after 3 months. 73 participants therefore completed the 6-month programme. Of these 73 participants, 72 completed both baseline and follow-up questionnaires at 6 months on at least HbAlc and medication data (97\% of 74 participants enrolled in the programme). Participants were aged $57.4 \pm 8.0$ years (range $30-70$ years) (table 1 ). The majority had a middle or higher education (76\%). Due to missing or invalid answers, data on secondary outcomes at 6 months are presented for fewer participants, varying from 34 to $65(47 \%-90 \%)$ per outcome measure.

\section{Primary outcome measures \\ HbA1c levels}

Participants had significantly lower Hb1Ac levels $(53.2 \pm 12.5 \mathrm{mmol} / \mathrm{mol})$ at 6 months compared with baseline $(58.3 \pm 12.0 \mathrm{mmol} / \mathrm{mol} ; \mathrm{p}<0.001$, table 2$)$. At baseline, 46 participants (64\%) had HbAlc-values above $53 \mathrm{mmol} /$ 
Table 1 Demographic characteristics of participants at baseline $(n=72)$

\begin{tabular}{|c|c|c|}
\hline & $\mathbf{N}$ & Mean \pm SD or $\%$ \\
\hline Age (years)* & 69 & $57.4 \pm 8.0$ \\
\hline \multicolumn{3}{|l|}{ Sex } \\
\hline Men & 32 & $44 \%$ \\
\hline Women & 40 & $56 \%$ \\
\hline \multicolumn{3}{|l|}{ Education level* } \\
\hline Low & 9 & $13 \%$ \\
\hline Middle & 47 & $65 \%$ \\
\hline High & 8 & $11 \%$ \\
\hline Missing & 8 & $11 \%$ \\
\hline \multicolumn{3}{|l|}{ Family structure* } \\
\hline $\begin{array}{l}\text { Married/cohabiting } \\
\text { without children (at } \\
\text { home) }\end{array}$ & 16 & $22 \%$ \\
\hline $\begin{array}{l}\text { Married/cohabiting with } \\
\text { children (at home) }\end{array}$ & 24 & $33 \%$ \\
\hline $\begin{array}{l}\text { Married/cohabiting with } \\
\text { children outside home }\end{array}$ & 16 & $22 \%$ \\
\hline $\begin{array}{l}\text { Single/living alone } \\
\text { without children (at } \\
\text { home) }\end{array}$ & 4 & $6 \%$ \\
\hline $\begin{array}{l}\text { Single/living alone with } \\
\text { children outside home }\end{array}$ & 4 & $6 \%$ \\
\hline $\begin{array}{l}\text { Single/living alone with } \\
\text { children (at home) }\end{array}$ & 3 & $4 \%$ \\
\hline Other & 2 & $3 \%$ \\
\hline Missing & 3 & $4 \%$ \\
\hline
\end{tabular}

*Data missing for age $(n=3)$, education level $(n=8)$ and family structure $(n=3)$.

mol and at 6 months, 29 participants $(40 \%)$ had a HbAlcvalue above $53 \mathrm{mmol} / \mathrm{mol}$.

Stratified analyses with a HbAlc-value below ('low starters') or above $53 \mathrm{mmol} / \mathrm{mol}$ ('high starters') at baseline showed a greater reduction in HbA1c in the 'high starters' than the 'low starters' after 6 months (see table 2 and online supplementary table 1 ). In the group of 'high starters' ( $\mathrm{n}=46)$, HbAlc levels were $8 \mathrm{mmol} /$ mol lower compared with baseline $(64.1 \pm 11.3 \mathrm{mmol} / \mathrm{mol}$ to $56.0 \pm 14.0, \mathrm{p}<0.001$ ), while no significant change was observed in the 'low starters' $(\mathrm{n}=26,48.1 \pm 2.3 \mathrm{mmol} / \mathrm{mol}$ to $48.1 \pm 7.1, \mathrm{p}=0.978$ ).
Use of glucose lowering medication

At baseline, 65 of the 72 participants (90\%) used glucose lowering medication (table 3 and figure 1). After 6 months, 35 of the 72 participants $(49 \%)$ used less glucose-lowering medication, of whom 9 participants $(13 \%)$ ceased all glucose-lowering medication (table 3 and online supplementary table 1$)$. Seven participants $(10 \%)$ who did not use medication at baseline still used no medication after 6 months.

\section{Secondary outcome measures}

Effects on other T2D biomarkers and health parameters

Participants had significantly lower fasting glucose level at 6 months $(-1.2 \pm 2.6 \mathrm{mmol} / \mathrm{L}, \mathrm{p}=0.001)$ (table 4$)$. Furthermore, body weight was $4.9 \pm 5.1 \mathrm{~kg}$ lower $(\mathrm{p}<0.001)$, waist circumference was $9.4 \pm 5.0 \mathrm{~cm}$ less $(\mathrm{p}<0.001)$ and BMI was $1.70 \pm 1.69 \mathrm{~kg} / \mathrm{m}^{2}(\mathrm{p}<0.001)$ lower at 6 months compared with baseline results. Although data on cholesterol-related values were available from only about half of the participants, the programme seemed to have had no effects on blood lipid profiles (table 4).

\section{Effects on subjective health parameters and physical activity}

Perceived self-reported health scores and quality of life were significantly higher compared with baseline $(p=0.001$ and $\mathrm{p}=0.022$, respectively) (table 4 ). Perceived fatigue (CIS-score) was significantly lower at 6 months $(-6.3 \pm 18.0$, $\mathrm{p}=0.016$ ). At 6 months, participants felt less fatigued, had higher levels of concentration and were more motivated to be physically active. In addition, participants also experienced fewer sleeping problems at 6 months $(\mathrm{p}=0.002)$. Furthermore, results showed that physical exercise at a moderate level was significantly higher at 6 months $(\mathrm{p}=0.013)$, but no significant change in intensive physical activity was observed $(\mathrm{p}=0.459)$.

Program adherence and appreciation

Results at 6 months showed $91 \%$ of the participants almost or almost fully (Likert scale 4-5) adhered to the nutrition guidelines for breakfast, $89 \%$ for lunch, $87 \%$ for the evening meal, $69 \%$ for snacks and $80 \%$ for drinks. Participants indicated that recommendations for breakfast, lunch and dinner were easy to follow. At the same time, participants reported more difficulties with skipping snacks, such as nuts and cheese in the afternoon and evening, and more difficulty avoiding certain drinks, such as a glass of wine at dinner or in the evening (results not shown). At 6 months, participants rated their appreciation of the programme with an average of $9.0 \pm 0.7$ out of 10 .

Table 2 Mean scores (SD) and change scores for HbA1c at baseline and at 6 months $(n=72)$

\begin{tabular}{llllll}
\hline & $\mathbf{N}$ & Baseline & $\mathbf{6}$ months $(\mathbf{n}=\mathbf{7 2})$ & Mean difference & $\mathbf{P}$ value \\
\hline HbA1c $\mathrm{mmol} / \mathrm{mol}$ & 72 & $58.3(12.0)$ & $53.2(12.5)$ & $-5.2(10.1)$ & $<0.001$ \\
Subgroup analyses & & & & & \\
$\quad \mathrm{HbA} 1 \mathrm{c}$ baseline $\geq 53 \mathrm{mmol} / \mathrm{mol}$ & 46 & $64.1(11.3)$ & $56.0(14.0)$ & $-8.1(10.5)$ & $<0.001$ \\
$\mathrm{HbA1c}$ baseline $<53 \mathrm{mmol} / \mathrm{mol}$ & 26 & $48.1(2.3)$ & $48.1(7.1)$ & $0.04(7.1)$ & 0.978 \\
\hline
\end{tabular}


Table 3 Number (and row percentage) of participants per medication class at baseline and 6 months $(n=72)$

\section{Medication class at 6 months}

\begin{tabular}{lcccccc}
\hline Medication class at baseline & Baseline & & No medication & Metformin & $\begin{array}{l}\text { Metformin+SU- } \\
\text { derivate }\end{array}$ & $\begin{array}{c}\text { Metformin +SU- } \\
\text { derivate+Insulin }\end{array}$ \\
\hline No medication & $7(10 \%)$ & 7 & 0 & 0 & 0 \\
Metformin & $13(18 \%)$ & 2 & 11 & 0 & 0 \\
Metformin+SU-derivate & $30(42 \%)$ & 5 & 17 & 7 & 1 \\
Metformin+SU-derivate+Insulin & $22(31 \%)$ & 2 & 8 & 1 & 11 \\
Subtotal & $72(100 \%)$ & $16(22 \%)$ & $36(50 \%)$ & $8(11 \%)$ & $12(17 \%)$ \\
\hline
\end{tabular}

\section{DISCUSSION}

The results of this proof-of-practice pilot study show that this 6-month multicomponent group-based nutrition and lifestyle intervention programme led to improved glucose control reflected by lower Hb1Ac levels and a reduction of glucose lowering medication use in motivated T2D patients. In addition, participants reported improvements in perceived quality of life, sleeping quality and fatigue and they showed high appreciation of the programme after 6 months.

The most noticeable effect was the reduction of glucose lowering medication. Overall, in $49 \%$ of the participants using glucose lowering drugs, it was considered medically justified to downscale their glucose lowering medication or even stop all glucose lowering medication completely within the 6 months of the programme (11 patients were able to come off insulin). This is in line with two recent international papers on the reversal of $\mathrm{T} 2 \mathrm{D}$ in obese patients, which also described that reduction of medication is achievable using intensive lifestyle and nutritional programmes. The DiRECT study ${ }^{35}$ as well as the VirtaHealth trial ${ }^{36}$ achieved a $46 \%-58 \%$ remission rate of T2D reflected by a reduction in $\mathrm{HbA1c}$ and reduction in medication use. The DiRECT study used a total, very low-calorie diet replacement and structured support for long-term weight loss management in 306 T2D patients. ${ }^{35}$ The VirtaHealth trial evaluated a novel care model providing

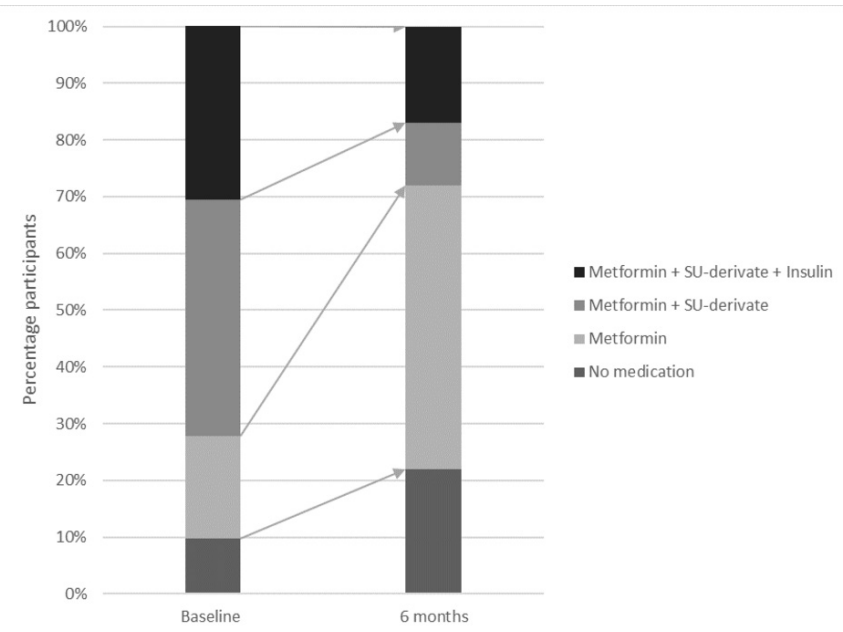

Figure 1 Percentage of participants who changed glucoselowering medication use from baseline to 6 months $(n=72)$. continuous remote care with medication management based on biometric feedback combined with nutritional ketosis in 349 T2D patients. ${ }^{36}$ Both the DiRECT and VirtaHealth study followed participants for 1 year. A reduction in medication use can contribute to reduced healthcare costs. We are currently performing a health economics analysis to elaborate further on this.

In this study, we observed an average weight loss of 4.9 $\mathrm{kg}$ at 6 months, a small but statistically significant weight reduction. The more ketogenic dietary approach of the VirtaHealth trial in T2D patients showed an average of 14 $\mathrm{kg}$ weight reduction in 12 months. ${ }^{36}$ Other studies found no effect of low-carbohydrate diets after 12 months, ${ }^{19}$ 24 months $^{18}$ and 64 months, ${ }^{20}$ respectively. Another lifestyle intervention programme in a prediabetes setting, the SLIMMER intervention (Netherlands), recorded an average of $2.5 \mathrm{~kg}$ weight reduction after 18 months. ${ }^{37}$ When comparing these studies, it is important to note that the participants included in this programme had a somewhat lower starting weight and BMI compared with previous studies; on average their starting weight was 93 $\mathrm{kg}$ versus $85 \mathrm{~kg}-114 \mathrm{~kg}$ in previous studies ${ }^{18-203637}$ and their BMI an average of $31 \mathrm{~kg} / \mathrm{m}^{2}$ versus $29-41 \mathrm{~kg} / \mathrm{m}^{2}$ in previous studies ${ }^{18-203637}$. Our results on body weight and $\mathrm{HbAlc}$ are similar to recent findings on the reversal of T2D. ${ }^{1424}$ Interventions based on intensive lifestyle change (eg, caloric restriction and exercise, energy restricted low carbohydrate, individual and group-based counselling as well as a ketogenic dietary approach and e-health/online monitoring) have generally shown a reduction in body weight between 3 and $14 \mathrm{~kg}$ within a period of 10-12 months. ${ }^{1424}$ Similarly, these lifestyle intervention studies reported a reduction of $\mathrm{HbAlc}$ of $5-15 \mathrm{mmol} / \mathrm{mol}$. Our study showed a reduction of $5 \mathrm{mmol} / \mathrm{mol}$ in $\mathrm{HbAlc}$ levels at 6 months. Differences in baseline characteristics (weight at onset of the programme, BMI, HbA1c, etc) of the participants in these studies may explain overall effect-size differences.

In addition, this study suggests that perceived quality of life improved and that people felt more energetic and less fatigued. This is in contrast to a systematic review by Snorgaard et al who found no improvements in quality of life assessed in 2 out of the 10 included randomised controlled trial (RCTs) of their systematic review. ${ }^{38} \mathrm{It}$ should be noted that not all participants completed the 
Table 4 Secondary outcomes: mean scores and change scores for health parameters, experienced health, quality of life, fatigue and physical activity at baseline and at 6 months

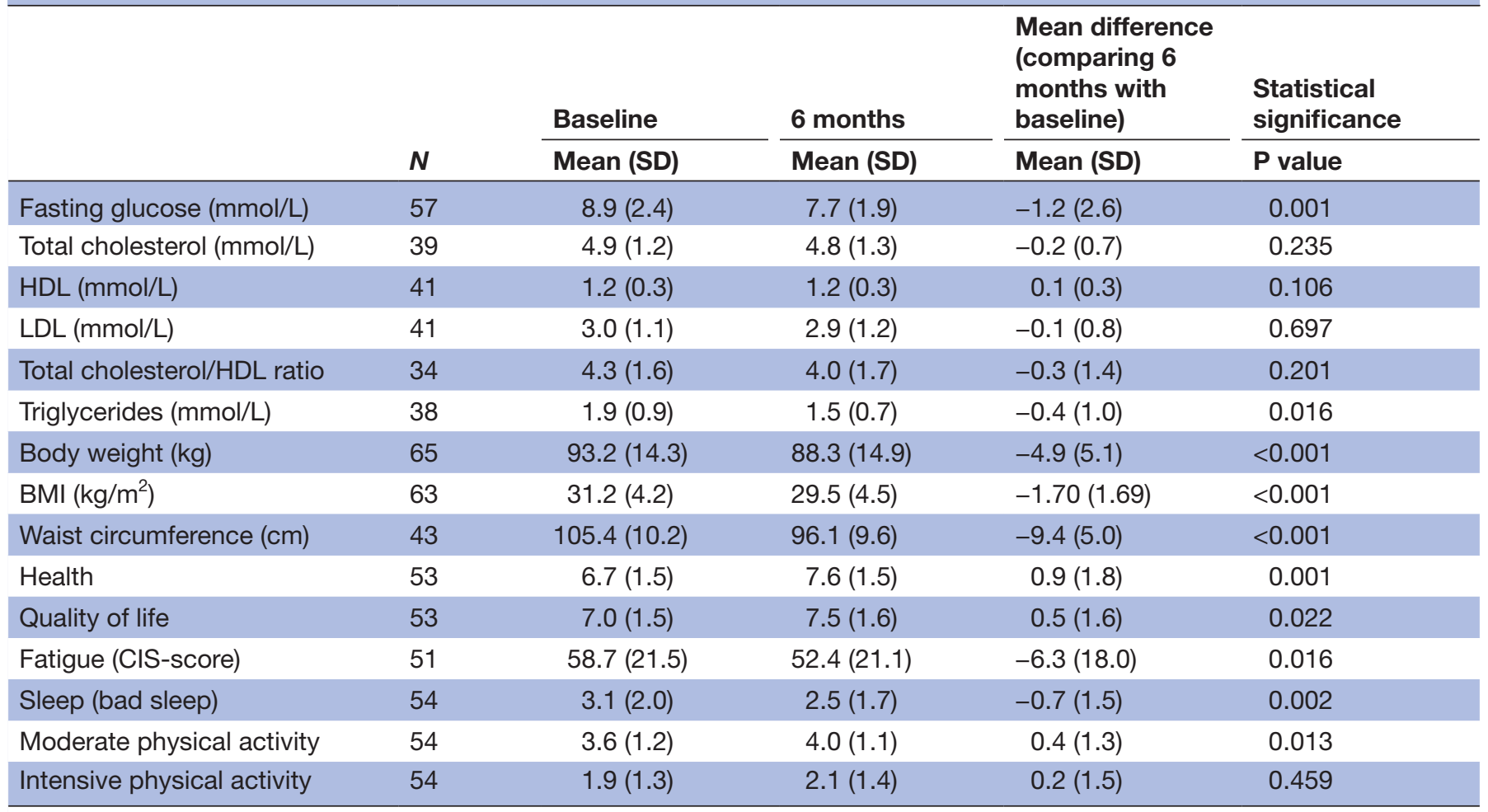

BMI, body mass index; CIS, Checklist Individual Strength.

questions on perceived quality of life and it may therefore be possible that different results would be found for those who have not completed the questionnaires. However, when comparing participant characteristics of those who have completed the questionnaires with the baseline data from the non-completers, we observed no or small differences in age, gender, education and medication use.

We acknowledge that caution should be taken when interpreting the results of this pilot study. First, this pilot study did not include a control group and had a relatively small sample size. We are currently scaling up this intervention programme and we will also compare the results with data from patients receiving standard medical care (using a quasi-experimental design). Another limitation is that participants of the programme joined the programme on their own initiative, which will inevitably cause selection bias in relation to their compliance and motivation to complete. In addition, participants were asked for financial contribution towards the costs of the intervention to stimulate intrinsic motivation, which may have led to a selection bias in towards people with greater financial means. However, if the financial contribution meant people were not able to participate, it was waived which in practice rarely occurred.

Data in this study are based on online questionnaires with self-reported answers, which may elicit socially desirable answers. However, questionnaires were completed anonymously and participants were instructed that there are no right or wrong answers. Moreover, validated questionnaires were used where possible (eg, CIS). A limitation of questionnaire-based studies can be the relatively low retention rates, especially in longer term studies, however, the attrition rate in this pilot study at 6 months was similar to other intervention studies. ${ }^{18} 35$ Finally, it should also be noted that medication use of participants was always managed by a healthcare professional (GP) and in accordance with standard medical practice. The investigators had no influence on possible changes in medication use.

The Voeding Leeft programme benefits from its practice-based and dynamic approach. At the same time, the proof of practice design of this study introduces constraints on accurate and optimal data-collection. It is advisable that future studies with higher numbers of participants pay specific attention to this issue. Considering the increasing attention for the use of lifestyle interventions as medicine and to ensure optimal data collection within a primary setting, the development of a dedicated infrastructure for data-collection and analysis would be desirable.

The primary outcomes of this evaluation study of the Voeding Leeft programme included medical and biochemical parameters, that is, Hb1Ac levels and medication use, and subjective health parameters such as quality of life. This pilot study and other studies have shown that it is possible to improve glucose control with a lifestyle intervention. However, sustainable adherence to a lifestyle change is crucial for its long-term success. This pilot study showed high appreciation of the programme and high adherence to the nutritional guidelines after 6 months. The present programme benefits from its 
multicomponent character, including the group-based approach as well as individual instant feedback, and addressing health literacy as well as health skills (eg, cooking classes). It would be interesting to follow participants after completing the 6-month intervention to gain insight in long-term effectiveness.

In conclusion, this pilot study indicates that this 6-month multicomponent programme led to improved glucose control and a reduction of glucose lowering medication use in motivated T2D patients. It provides a step in the direction of more practice-based evidence but a fully scaled study is needed to confirm these results.

\section{Author affiliations}

${ }^{1}$ Department of Nutrition and Health, Louis Bolk Instituut, Bunnik, The Netherlands ${ }^{2}$ King's College London, Division of Diabetes and Nutritional Sciences, London, UK ${ }^{3}$ Division of Internal Medicine, Leids Universitair Medisch Centrum, Leiden, The Netherlands

${ }^{4}$ Division of Human Nutrition and Health, Wageningen Universiteit, Wageningen, The Netherlands

${ }^{5}$ Department of Neurology, AMC, Amsterdam, The Netherlands

${ }^{6}$ General Practitioner, Medical Centre te Cleeff, Haarlem, The Netherlands

${ }^{7}$ Springh, Den Haag, The Netherlands

Acknowledgements We are indebted to the participants of the pilot program 'Reverse Diabetes2'. Furthermore, we thank Lotte Schaffer for her help in data collection. We thank Connie Hoek, Nicole de Groot, Ronal Gier, and Ben van Ommen for their contributions in the developmemt of the programme.

Contributors GKP and MCEB-F analysed the data, and drafted and revised the manuscript; ONP and NvdZ drafted and revised the manuscript. HP and RFW are members of the scientific advisory board of Voeding Leeft, and provided scientific input to design of the study and manuscript. MdV provided scientific input to the design of the study and manuscript. PJV designed the lifestyle intervention, drafted and revised the manuscript and is responsible for the overall content of the manuscript (guarantor). PJV is also co-founder of the Voeding Leeft Foundation.

Funding This work was supported by VGZ Health Insurance via the foundation Voeding Leeft and by Ekhaga (application number 2017-55).

Competing interests GKP, MCEB-F, ONP and PJV report grants from Ekhaga Foundation, grants from Voeding Leeft, during the conduct of the study; MdV reports personal fees from null, outside the submitted work; RFW reports that he is member (chair) of the scientific advisory board (Deelnemersraad) of the Voeding Leeft Foundation, for which he receives no financial or other compensation; HP and NvdZ have nothing to disclose; no financial relationships with any organisations that might have an interest in the submitted work in the previous 3 years, no other relationships or activities that could appear to have influenced the submitted work.

Patient consent for publication Not required.

Ethics approval This study was approved by Healthcare partners Friesland.

Provenance and peer review Not commissioned; externally peer reviewed.

Data sharing statement All data relevant to the study are included in the article or uploaded as supplementary information.

Open access This is an open access article distributed in accordance with the Creative Commons Attribution Non Commercial (CC BY-NC 4.0) license, which permits others to distribute, remix, adapt, build upon this work non-commercially, and license their derivative works on different terms, provided the original work is properly cited, appropriate credit is given, any changes made indicated, and the use is non-commercial. See: http://creativecommons.org/licenses/by-nc/4.0/.

\section{ORCID iD}

Gerda K Pot http://orcid.org/0000-0002-0863-4484

\section{REFERENCES}

1. Global report on diabetes who library Cataloguing-in-Publication data. Available: http://www.who.int/about/licensing/ [Accessed 15 Jun 2018].
2. Tuomilehto J, Lindström J, Eriksson JG, et al. Prevention of type 2 diabetes mellitus by changes in lifestyle among subjects with impaired glucose tolerance. $N$ Engl J Med Overseas Ed 2001;344:1343-50.

3. Taylor R. Type 2 diabetes: etiology and reversibility. Diabetes Care 2013;36:1047-55.

4. Ajala O, English P, Pinkney J. Systematic review and meta-analysis of different dietary Approaches to the management of type 2 diabetes. Am J Clin Nutr 2013;97:505-16.

5. Steven S, Lim EL, Taylor R. Population response to information on reversibility of type 2 diabetes. Diabet Med 2013;30:e135-8.

6. De Vries M, Witkamp R, de Weijer T. Re: beating type 2 diabetes into remission: a consensus-based working definition. BMJ 2017;358.

7. Sjöström L, Lindroos A-K, Peltonen $M$, et al. Lifestyle, diabetes, and cardiovascular risk factors 10 years after bariatric surgery. $N$ Engl $J$ Med 2004;351:2683-93.

8. Karter AJ, Nundy S, Parker MM, et al. Incidence of remission in adults with type 2 diabetes: the diabetes \& aging study. Diabetes Care 2014;37:3188-95.

9. Wing RR, Blair E, Marcus M, et al. Year-long weight loss treatment for obese patients with type II diabetes: does including an intermittent very-low-calorie diet improve outcome? Am J Med 1994;97:354-62.

10. Steven $\mathrm{S}$, Hollingsworth KG, Al-Mrabeh A, et al. Very lowcalorie diet and 6 months of weight stability in type 2 diabetes: pathophysiological changes in responders and nonresponders. Diabetes Care 2016;39:808-15.

11. Gumbiner B, Wendel JA, McDermott MP. Effects of diet composition and ketosis on glycemia during very-low-energy-diet therapy in obese patients with non-insulin-dependent diabetes mellitus. Am J Clin Nutr 1996;63:110-5.

12. Saslow LR, Kim S, Daubenmier JJ, et al. A randomized pilot trial of a moderate carbohydrate diet compared to a very low carbohydrate diet in overweight or obese individuals with type 2 diabetes mellitus or prediabetes. PLoS One 2014;9:e91027.

13. Nielsen JV, Joensson EA. Low-carbohydrate diet in type 2 diabetes: stable improvement of bodyweight and glycemic control during 44 months follow-up. Nutr Metab 2008;5.

14. Tay J, Luscombe-Marsh ND, Thompson $\mathrm{CH}$, et al. Comparison of low- and high-carbohydrate diets for type 2 diabetes management: a randomized trial. Am J Clin Nutr 2015;102:780-90.

15. Westman EC, Yancy WS, Mavropoulos JC, et al. The effect of a lowcarbohydrate, ketogenic diet versus a low-glycemic index diet on glycemic control in type 2 diabetes mellitus. Nutr Metab 2008;5.

16. Boden G, Sargrad K, Homko C, et al. Effect of a low-carbohydrate diet on appetite, blood glucose levels, and insulin resistance in obese patients with type 2 diabetes. Ann Intern Med 2005;142:403-11.

17. Yancy WS, Foy M, Chalecki AM, et al. A low-carbohydrate, ketogenic diet to treat type 2 diabetes. Nutr Metab 2005;2.

18. Iqbal N, Vetter ML, Moore RH, et al. Effects of a low-intensity intervention that prescribed a low-carbohydrate vs. a low-fat diet in obese, diabetic participants. Obesity 2010;18:1733-8.

19. Wolever TMS, Gibbs AL, Mehling C, et al. The Canadian trial of carbohydrates in diabetes (ccd), a 1-y controlled trial of lowglycemic-index dietary carbohydrate in type 2 diabetes: no effect on glycated hemoglobin but reduction in C-reactive protein. Am J Clin Nutr 2008;87:114-25.

20. Brinkworth GD, Noakes M, Parker B, et al. Long-term effects of advice to consume a high-protein, low-fat diet, rather than a conventional weight-loss diet, in obese adults with type 2 diabetes: one-year follow-up of a randomised trial. Diabetologia 2004;47:1677-86.

21. McKenzie AL, Hallberg SJ, Creighton BC, et al. A novel intervention including individualized nutritional recommendations reduces hemoglobin A1c level, medication use, and weight in type 2 diabetes. JMIR Diabetes 2017;2:e5

22. Bauman WA, Schwartz E, Rose HG, et al. Early and long-term effects of acute caloric deprivation in obese diabetic patients. Am J Med 1988;85:38-46.

23. Dashti HM, Mathew TC, Khadada M, et al. Beneficial effects of ketogenic diet in obese diabetic subjects. Mol Cell Biochem 2007;302:249-56.

24. Wing RR, Look AHEAD Research Group. Long-term effects of a lifestyle intervention on weight and cardiovascular risk factors in individuals with type 2 diabetes mellitus: four-year results of the look ahead trial. Arch Intern Med 2010;170:1566-75.

25. Wolf AM, Conaway MR, Crowther JQ, et al. Translating lifestyle intervention to practice in obese patients with type 2 diabetes: improving control with activity and nutrition (ICAN) study. Diabetes Care 2004;27:1570-6. 
26. Di Onofrio V, Gallé F, Di Dio M, et al. Effects of nutrition motivational intervention in patients affected by type 2 diabetes mellitus: a longitudinal study in Naples, South Italy. BMC Public Health 2018;18.

27. Harris SB, Petrella RJ, Leadbetter W. Lifestyle interventions for type 2 diabetes. Relevance for clinical practice. Can Fam Physician 2003;49:1618-25.

28. Green LW. Making research relevant: if it is an evidence-based practice, where's the practice-based evidence? Fam Pract 2008;25 Suppl 1:i20-4.

29. Greenhalgh T, Howick J, Maskrey N, et al. Evidence based medicine: a movement in crisis? BMJ 2014;348:g3725.

30. Greaves CJ, Sheppard KE, Abraham C, et al. Systematic review of reviews of intervention components associated with increased effectiveness in dietary and physical activity interventions. BMC Public Health 2011;11.

31. Lim S, Kang SM, Kim KM, et al. Multifactorial intervention in diabetes care using real-time monitoring and tailored feedback in type 2 diabetes. Acta Diabetol 2016;53:189-98.

32. Nederlandse Diabetes Federatie. NDF Voedingsrichtlijn voor diabetes, 2015. Available: http://www.zorgstandaarddiabetes.nl/wp-
content/uploads/2015/06/DEF-NDF-Voedingsrichtlijn-Diabetes-2015versie-1.3.pdf [Accessed 3 May 2017].

33. Rutten G, De Grauw W, Nijpels G, et al. NHG-Standaard diabetes mellitus type 2 |NHG. Huisarts Wet 2013;56:512-25.

34. Vercoulen JH, Alberts M, Bleijenberg G. De checklist individuele spankracht (cis). Gedragstherapie 1999;32.

35. Lean MEJ, Leslie WS, Barnes AC, et al. Primary care-led weight management for remission of type 2 diabetes (direct): an open-label, cluster-randomised trial. The Lancet 2018;391:541-51.

36. Hallberg SJ, McKenzie AL, Williams PT, et al. Effectiveness and Safety of a Novel Care Model for the Management of Type 2 Diabetes at 1 Year: An Open-Label, Non-Randomized, Controlled Study. Diabetes Ther 2018;9:583-612.

37. Duijzer G, Haveman-Nies A, Jansen SC, et al. Effect and maintenance of the slimmer diabetes prevention lifestyle intervention in Dutch primary healthcare: a randomised controlled trial. Nutr Diabetes 2017;7:e268.

38. Snorgaard O, Poulsen GM, Andersen HK, et al. Systematic review and meta-analysis of dietary carbohydrate restriction in patients with type 2 diabetes. BMJ Open Diabetes Res Care 2017;5:e000354. 